\title{
Government Underpinning: Failure to Abolish Consumer Slavery
}

\author{
Amari Teal \\ Xavier University of Louisiana, New Orleans, LA, USA
}

\begin{abstract}
This paper will assess the way in which consumerism is used to manipulate individuals within marginalized groups, specifically those based on race and gender. Following a Marxist framework, this paper will illustrate a symbiotic relationship between the laborer and the capitalist, a hierarchal relationship where mutual dependence encourages unrelenting exploitation. Further focus will center on how these social hierarchies perpetuate a continuous enslavement of individuals politically defined as black and politically defined as woman. These identities are outlined within the framework of two active dichotomies: black/white and man/woman. Both gender and race are key factors in determining an individual's identity. Because the hegemonic gender is man, while the hegemonic race is white, any person who does not fit into those two categories simultaneously is underprivileged. Hence the reason why black and woman, both of which have been historically deemed subordinate to white and man, is automatically a part of the underprivileged working class. Since the hierarchal laborer-capitalist relationship is greatly validated by socializations, it cannot be voided by taking legal action alone. However, policy changes addressing education gaps, gender wage gaps, and hiring discrepancies, can assist in decoupling the social constructs of race and gender from class therefore minimizing racial and gender privileges.

Keywords: social construct, capitalism, consumerism, dichotomies, hegemonic masculinity, Blind Hiring, occupational segregation
\end{abstract}

\section{Introduction}

Both race and gender are social constructs created to categorize individuals by specific differences for the purpose of marginalization. Black/white races are not valid ethnic categories, although individuals have been socialized to believe that they are. This paper will focus on how, given perpetuation of the social constructs of race and gender in the context of socioeconomic status, slavery still exists in the United States of America today. Additional focus will be on how those who buy into the constructs of race and gender continue to financially support the government which keeps them enslaved.

\section{Sociohistorical Context of Race and Slavery}

The social construct of slavery, within the context of the transatlantic slave trade, began as an economic venture: A means of capitalizing on resources present in what would eventually be known as the United States of America by means of involuntary labor (Dorris, 2007). Slavery was not only a way to segregate American citizens, but to ensure that the economy would continue to thrive (Dorris, 2007). Over time slavery in the 
Americas became notorious for its massive efficiency in producing goods, and violence against people socially defined as black. In 1865, when the 13th amendment was ratified, slavery and involuntary servitude were both prohibited.

Slavery, having been commonly misinterpreted only as an aesthetic "shackles and whips" ideal, a visage of people being held violently against their will and forced to labor relentlessly, was never defined as a social construct or mindset. Following the abolition of slavery and involuntary servitude, the constructs of race, and socioeconomic status, became related symbiotically. A United States of America without the "shackles and whips" version of slavery meant that all ethnic groups were on equal playing fields to whites. In order to combat this, nonwhite ethnic groups were added to the already established caste system at the very bottom: white men occupying the highest rung on the ladder and black women occupying the lowest rung. Thus the social construct of slavery was transformed from the physiological, based on differences in human morphology, to the psychological, based on socializations regarding said differences. Post-slavery, racial distinction was maintained through socialization and psychological paradigms that maintained marginalization.

\section{Sociohistorical Context of Hegemonic Masculinity and Gender}

Gender inequalities have existed in various cultures from the beginning of time. Since a culture is defined as a set of beliefs and customs of social group (Loflin, 1976), it follows logically that social constructs such as race and/or gender were used as tools to smuggle the beliefs in. The idea that maleness is hegemonic is androcentric in origin. While androcentric beliefs lay at the base of patriarchy, they had to have come from somewhere. Ethnocentrism as a form of "group narcissism" (Bizumic \& Duckitt, 2008), is the belief that ones culture is superior to the rest, which encourages androcentric ideologies in the context of gender. Hegemonic masculinity as an androcentric ideology is both the idea that maleness is superior to femaleness, and that there are certain forms of maleness that are superior to others. Cultures are the vehicles in which social constructs dictate group ideologies.

In American culture, women and men have been socialized to believe in the Sex-Gender System. The Sex-Gender System currently upholds the idea that humans with a penis are men and humans with a vagina are women. It also allots gender roles to each (Rubin, 2011). Historically, in the social sphere where women were expected to be weak and submissive while men were expected to be strong and commanding, patriarchy was the key oppressor of women. Since then, such gender roles have become systematic in that male qualities are upheld more than female qualities within the professional realm. Feminist theorist Alison Jaggar hypothesizes that today there is a two systems explanation for women's oppression: Capitalism is working hand and hand with patriarchy to oppress women both as workers and as women (Tong, 2014a). This Sex-Gender System does not take into consideration that not everyone identifies with the same gender as their phenotypic form suggests let alone any gender at all. Gender distinction, similar to racial distinction, was also maintained through socialization and psychological paradigms that preserved marginalization. Both race and gender were created by giving arbitrary physical human characteristics some social relevance in an attempt to sustain a system of hierarchy. Although each of the two social constructs are more complex, this paper will evaluate the intersectionality of only two active dichotomies: black/white to address race, and man/woman to address gender. 


\section{Allegory on Consumption}

The connection between race, gender, and class resembles an unfair marathon between four different individuals: one white man, one white woman, one black man, and one black woman. Each participant gets two boxes, one of race and the other of gender, and must run the entire race toting the boxes behind them. There are four boxes: one full of feathers, one full of leaves, one full of branches, and another full of bricks. Ideally, if given a choice, a person would select a box of feathers over the box of bricks. However, in this race, each runner must carry the weight of their identities, a weight of which is not a choice. As are racialized/gendered identities, these boxes are assigned instead of chosen. As the hegemonic gender, both men will receive gender boxes consisting of leaves. In the race box however, the man politically defined as white will have feathers while the man politically defined as black will have bricks. Likewise, both women will have gender boxes full of branches, a noticeably heavier burden than the leaves present in the gender boxes of their male counterparts. Yet in the race box, a white woman will have feathers while the black woman has bricks.

The marathon is weighted in the sense that none of the participants are knowledgeable about what is in each of the boxes. If they never know for sure what each box contains, they are never able to address the advantages or disadvantages present within the marathon. The runners do not always start at the same point: those of more affluence start closer to the finish line than those of less affluence. Class is not only represented by the place an individual starts, but the place where an individual finishes as well. Class shows the potential for opportunity based on an individual's performance within the context of race and gender. A person toting around bricks and branches has a smaller likelihood of winning first place over a person who is carrying feathers and leaves no matter the starting point. The capitalist system is the entity encouraging people with clear disadvantages to continue running the marathons because there is still a chance they could win. In a system which is constantly evolving to maintain social positions, more people seek to fit perfectly within a category: first place, second place, third place. Furthermore, individuals employ the fluidity of their categories by continuing to run the race signaling proximity along the way: conspicuous consumption. This consumption coupled with the individual's insatiable need to win the race constructs a neo-enslavement.

\section{Capitalism and Consumerism}

Citizens within the United States of America are currently enslaved by Capitalism. The most underprivileged citizens are automatically the proletariat: the laborers and the consumers (Tong, 2014a). They are encouraged to make purchases to prove their wealth because the wealthier a person appears to be, the higher class they are assumed, and the more opportunities they are afforded. For example: "Certain Sports, particularly basketball, function as sites where black men are commonly allowed full access to "American" masculinity" (Miner, 2009, p. 77). By “American masculinity”, Miner addresses the idea of hegemonic masculinity within the United States of America as a function of one's whiteness and maleness. As sports are one of the few loci where hegemonic masculinity is reserved for black men, it is no surprise that basketball is most popular amongst that group. Miner outlines Chuck Taylors, in competition with Keds and P.F. Flyers, as the hegemonic shoe for basketball players, and illustrates how by "the 1960s there developed an established structure of allowable fashion that 'authentic' ball players needed to follow to be accepted within its cultural domain" (Miner, 2009, p. 79). Shoe companies have marketed these specific sneakers to aspiring basketball players, a large portion of that demographic being young black men. During the 60s it was acceptable for individuals who 
had not yet reached NBA status to only wear Chuck Taylor's. However,

Once a player gained a certain level of prestige or credibility with their peers, they were capable of transcending the established structure of acceptable footwear. Serious ball players could wear Keds, but never P.F. Flyers. At the same time, everyone else needed to sport Chuck Taylors to allow them entrée into the masculine sphere of hoops culture. (Miner, 2009, pp. 79-80)

Chuck Taylors symbolized success, wealth, and coolness: qualities which appeal to the masses. Sneakers not only became a symbol of collective identity, which underpin black masculinity, but they became an item of conspicuous consumption as well. Developing sports as the arena for black hegemonic masculinity allows black men to see sneakers not only as the symbolic vehicle for that expression, but as an essential part of their racialized and gendered identity.

Marginalized groups have a lower likelihood of being educated, and a greater chance of being impoverished which makes them the perfect targets for business marketers. If the bourgeoisie are able to convince the proletariat that the product at hand is both essential to the proletariat's identity and makes them appear somewhat superior, said person would be more likely to make the purchase. Because the poor do not want to remain poor, they mistake "looking" wealthy for "being" wealthy, and proceed to conspicuously consume items/services such as Jordan shoes, 24 inch rims, Louis Vuitton purses, hair extensions, and acrylic manicures in order to appear as if they belong to a certain race, gender, and/or class. In the same way the continuous running of a marathon signaling proximity projects one's self as further along in the race, conspicuous consumption acts as an extension of one's racialized and gendered buying behaviors to create the illusion that one is further along financially.

While the poor are persuaded into conspicuous consumption of items with depreciating value, the rich are urged to project their wealth through investment in stock which will generate greater monetary value over time. Furthermore, as different races and genders are encouraged into such buying behaviors, they are urged to engage in identity confirming purchases. Considering the two active dichotomies man/woman and black/white, many intersectional identities exist. Identity confirming behavior is engrained into unconscious minds, and is constantly upheld. Individuals will be less surprised if a black woman purchases Louis Vuitton purses for herself every month rather than financing a house because that buying behavior is expected of a black woman specifically. However, a white man purchasing Louis Vuitton purses for himself every month rather than financing a house may not have as much support because his buying behaviors are both gender and race disconfirming. The encouragement of this public buying behavior ensures that proletariats will always exist to labor for and buy from the Bourgeoisie: A phenomenon which makes the rich even wealthier, and the poor even more underprivileged. Class stratifications on the basis of race and gender will remain intact as long as individuals comply with their assigned identities and consumption patterns.

\section{Policy Changes to Combat Enslavement}

The key to combatting this enslavement is attacking the social constructs to weaken the system of inequalities. Kate Millett suggested that gender is eliminated because gender was constructed under patriarchy and therefore benefits men more than women (Tong, 2014a). In theory, a world without gender would mean a world without gender inequalities. Taking Millett's suggestion a step further, a world without race or gender would mean a world without racial and gender inequalities. If all social constructs were treated as such, rather than being treated as valid biologically sound categorical representations of people, the capitalist system would 
not have as extensive a consumer paradigm to enslave citizens. Since the hierarchal laborer-capitalist relationship is greatly validated by socialization, it cannot be voided by taking legal action alone. However, policy changes addressing education gaps, gender wage gaps, and hiring discrepancies, can assist in decoupling the social constructs of race and gender from class, therefore minimizing racial and gender privileges.

\section{Addressing Hiring Discrepancies}

Currently, hiring policy is intended to be nondiscriminatory. It is failing to prevent discrimination based on gender and race because it is focused on meeting numerical expectations for certain demographics. These numbers were productive at a time when discrimination was overt, but as time elapsed, discrimination became adverse and these expectations became counterproductive. Affirmative action was a way to ensure nonwhite individuals an opportunity, one which they may have been well qualified for, at a time where their qualifications were devalued because of their racialized and gendered identities. As education of women and nonwhite identifying individuals came to include all disciplines afforded to white men, women were no longer confined to arts and domestic curriculum and nonwhite identifying people were no longer confined to technical and service related curriculum (Tong, 2014b).

More individuals of various demographics are pursuing higher education and obtaining qualifications for more jobs due to the decline in educational discrepancies based on race and gender. One common misconception about Affirmative Action is that for the sake of inclusion, employers are legally forced to turn away qualified individuals. While an employer may have to turn away some qualified individuals, as a result of that particular policy, the same employer is not forced to hire underqualified individuals. At the same time, some may support Affirmative Action because it forces employers to consider a qualified individual who, without such a policy in place, would have not been selected at all because of their race and/or gender. While this policy was necessary at a time where equal opportunity was not afforded to all, it did not prove successful in replicating equal results (Dorris, 2009). Since there is no method to measure whether or not an individual was hired based on qualifications, independent of their race and/or gender, these common misconceptions are valid. The only true way to gage the likelihood that an individual was hired based only on their qualifications is to create a hiring process which focuses on the skills necessary: engagement in a blind hiring process.

\section{Occupational Inequalities Based on Race and Gender}

In an experiment carried out by Devah Pager, the effect of race and felony on a job applicant's chances of advancing to the interview process was measured. Working within the black/white dichotomy for men, it was found that race, rather than felony record had a greater impact on whether or not a person was selected. Four identities were used: black man with felony, black man without felony, white man with felony, white man without felony. The individuals who were selected followed this order of popularity: white men without a felony, white men with a felony, black men without a felony, and last, black men with a felony (Pager \& Quillian, 2005). Why was the white man with a felony more likely to be selected than the black man without one? This audit proved that discrimination based on race still exists and significantly minimizes opportunities for people politically defined as black in the professional world.

Although this experiment did not compare women of each race with their male counterparts; it is likely that a gap would have been found. It follows logically that women and men may have varying likelihoods at being selected for different jobs. For example, a woman may have an advantage over a man if they are both 
applying to be Kindergarten teachers. According to the U.S. Bureau of Labor Statistics, in 2013, 2.2\% of all preschool and Kindergarten teachers were male. This statistic proves that there is some discrimination against men when selecting individuals for female dominated occupations. Occupational segregation and gender wage gaps are the results of early childhood gendered socializations (Kalantari, 2012) manifesting themselves within the work force.

In the median weekly earning of a full time wage/salary worker in 2012 was $\$ 879$ for white men, and $\$ 665$ for black men. White women made $80 \%$ of what their male counterparts made whereas black women made $95 \%$ of what their male counterparts made. This means that black women made about $68 \%$ of what white men made in similar occupations. The wage gaps are the result of discriminatory hiring practices and wage negotiations. In order to avoid such discrimination, certain changes must be made to the hiring process. The author proposes that ethnicity and gender are omitted completely from the application process, while names and addresses are withheld until after wage negotiations have been made.

Names and addresses are key signifiers of particular racial and gendered demographics. If asked to select the man's name, given the two names Sally and John, one is more likely to select John. Furthermore, if asked to choose the white woman when given the two names Sally and Sondra, one is more likely to select Sally. With unique names such as Ahmid, Sharonda, Thuy-Vy, Rohan, and Dante, all of which paint distinct races and genders, it is not realistic to expect every person to have a unisex name like Riley or Sam which appeal to Eurocentric standards. In order to bypass any prejudices a specific type of blind hiring is in order.

\section{Blind Hiring Process}

Using an arbitrary numerical value such as the last four digits of the social security number instead of names, gender, ethnicity, and addresses for the application and interview processes may aid in the reduction of discrimination. Creation of an interview environment based on the job expectations rather than personal evaluation may prompt the employer to focus more on choosing qualified candidates independent of conscious or subconscious preference. This may also encourage a fairer wage negotiation which would substantially decrease the gender wage gaps. In this blind application/blind interview process, neither the potential employer nor the potential employees are conscious of each other's identities: They do not see or hear one another as they would normally look and sound.

A study was done to test whether or not race or sex influenced the musician selection for some major U.S. Symphony Orchestras. In this study, musicians performed behind a screen, with neither their bodies seen nor their voices heard, and were identified by an arbitrary number. This blind audition process increased the chances of a female musician advancing past the preliminary round. Furthermore, it lead to "one-third of the increase in the proportion female among new hires" (Goldin \& Rouse 2000). This study proved that blind hiring is effective in increasing the amount of gender diversity within male dominated occupations. If the interview processes for all businesses were modeled after the Symphony Orchestra's blind auditions, interviews would be based off of the applicant's ability to perform efficiently which may increase the diversity and quality of employees.

If businesses are in fact equal opportunity employers, it is not necessary for them to know an individual's ethnic background or gender prior to getting to know that individual on a personal level. The fact that a business may actually require disclosure of gender and ethnicity suggests that they may have the power to discriminate without being obligated to admit that discrimination. 
It is possible to eliminate discrimination in the hiring process, but increasingly difficult to eliminate discrimination post hiring. One may inquire about how we would measure whether or not employees of varying races and genders had been hired and discriminated against in the work place if we are not supplied with their personal identification? The simplest solution to obtain such statistics is to provide a survey for the company's employees where they are able to provide ethnicity, gender, income, and evaluations on company practices.

\section{Conclusion}

By attacking wage gaps, education gaps, and other occupational inequalities based on race, class, and gender that plague the social sphere today, we are weakening the social constructs. Not only might this phenomenon lead to a more equitable professional world, but encourage a more equitable social ideology as well. People may feel less attached to race and gender as they do to humanness. This may decrease the socialized buying behaviors and consequentially decrease the financial gain of companies which rely on race and gender differences to make money. It may also help individuals realize that not only do they have an identity independent of products, but an identity that only they have the power to define as well. It is not defined by the color of their skin or the type of genitals they have. It is not defined by other people. That conscious awakening alone minimizes this neo-slavery.

\section{References}

Bizumic, B., \& Duckett, J. (2008). My group is not worthy of me: Narcissism and Ethnocentrism. Political Psychology, 29(3), 437-53.

Dorris, R. (2007). Navigating distant shores: A historical overview. In R. D. Littleton (Ed.), Perspectives in African American history and culture: An introductory reader (pp. 1-21). MA: Tapestry Press.

Dorris, R. (2009). Race as a social construct: The impact on education. Urbana:IL.

Goldin, C., \& Rouse, C. (2000). Orchestrating impartiality: The impact of "Blind” Auditions on female musicians. The American Economic Review, 90(4), 715-741.

JBHE. (1997). A Note on Tokenism in Higher Education: Dealing the Race Card. The Journal of Blacks in Higher Education, 18, 18.

Kalantari, B. (2012). The influence of social values and childhood socialization on occupational gender segregation and wage disparity. Public Personnel Management, 41(2), 241-255.

Loflin, M. D. (1976). A culture as a set of beliefs. Current Anthropology, 17(4), 723-25.

Miner, D. (2009). Provocations on sneakers: The multiple significations of athletic shoes, sport, race, and masculinity. The New Centennial Review, 9(2), 73-107.

Pager, D., \& Quillian, L. (2005). Walking the talk? What employers say versus what they do. American Sociological Review, 70(3), 355-77.

Pietrykowski, B. (2009). The political economy of consumer behavior: Contesting consumption. Abingdon, Oxon: Routledge.

Rubin, G. (2011). The traffic in women. In G. R. Durham (Ed.), Deviations: A Gayle Rubin Reader (pp. 33-65). North Carolina: Duke University Press.

The U.S Census Bureau. (2012). Income, poverty, and health insurance coverage: Retrieved from https://www.census.gov/newsroom/releases/pdf/20130917_ipslides.pdf

The U.S. Bureau of Labor Statistics. (2014). Women in the labor force: A databook. Retrieved from: http://www.bls.gov/cps/wlf-databook-2013.pdf

Tong, R. (2014a). Marxist and socialist feminism: Classical and contemporary. In R. T. Boulder (Ed.), Feminist thought: A more comprehensive introduction (pp. 93-125). Colorado: Westview Press.

Tong, R. (2014b). Women of color feminisms. In R. T. Boulder (Ed.), Feminist thought: A more comprehensive introduction (pp. 211-53). Colorado: Westview Press. 